\title{
EPS Council in session in Oslo
}

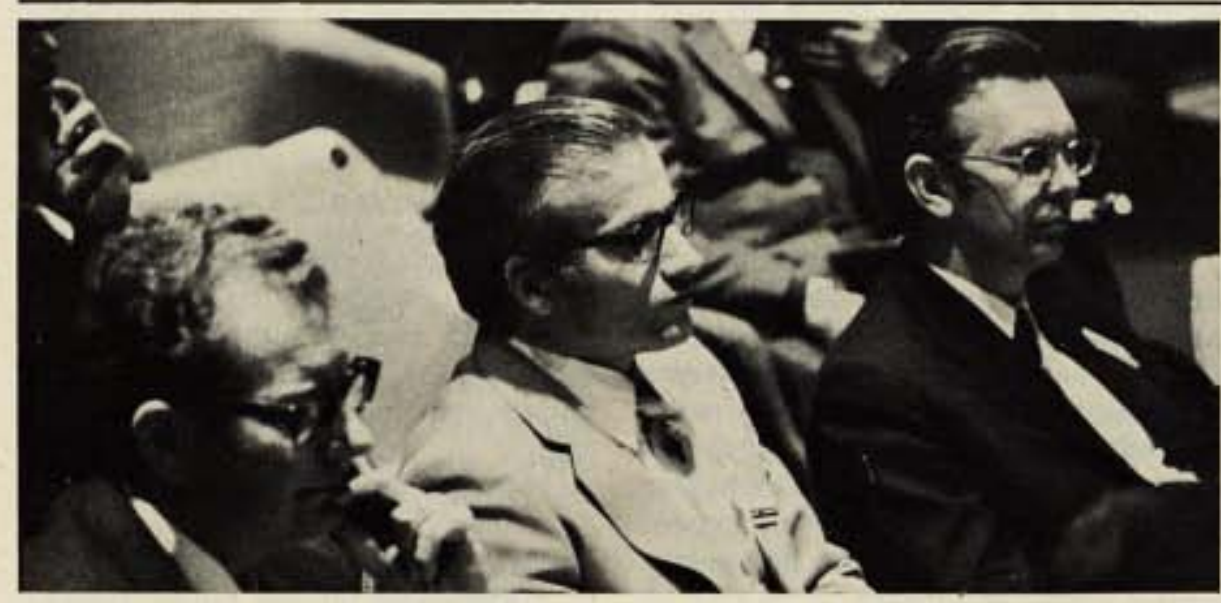

From the German Physical Society, E. Aichtor, W. Martienssen and H.F. Schopper attend the proceedings.

Executive Committee members from East Eu. ropean countries N. Cindro, L. Artstmovich, and G. Szigettl, and on their right, Europhysics News Editor, A.H. Crawford.
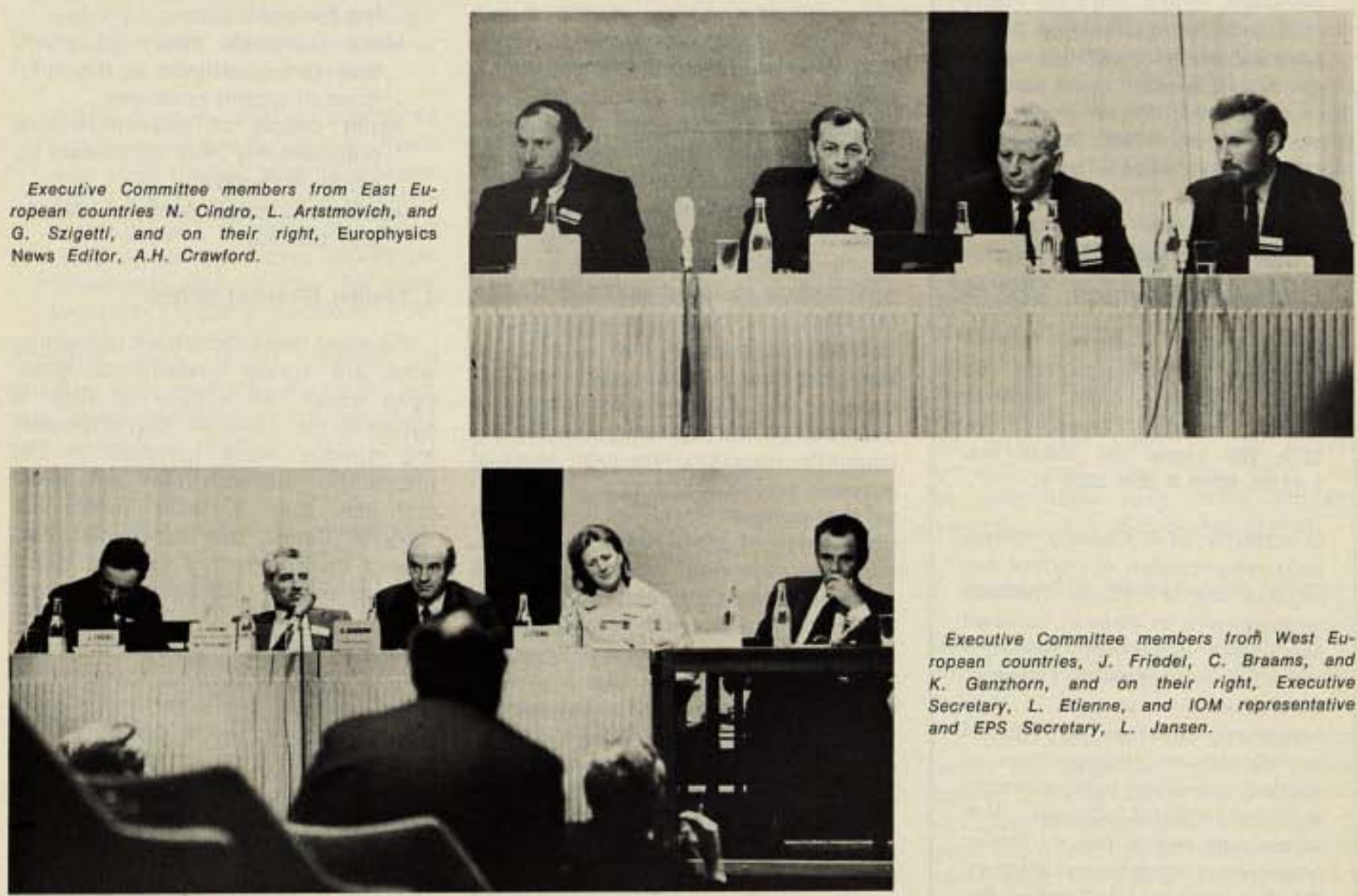

Executive Committee members from West Enropean countries, J. Friodel, C. Braams, and $K$. Ganzhorn, and on their right, Executive Secretary, L. Etienne, and IOM representative and EPS Secrotary, L. Jansen.

EPS Council members concentrate as Q.H. Stafford, Chairman of the Advisory Committeo on Publications, concludes his report. Back row: L.A.A. Thomas and R. Pross. Middle row : J. Depireux, G.H. Stafford and $N$. Kurti.

Front row: P. Radvanyi and A. Guinier.

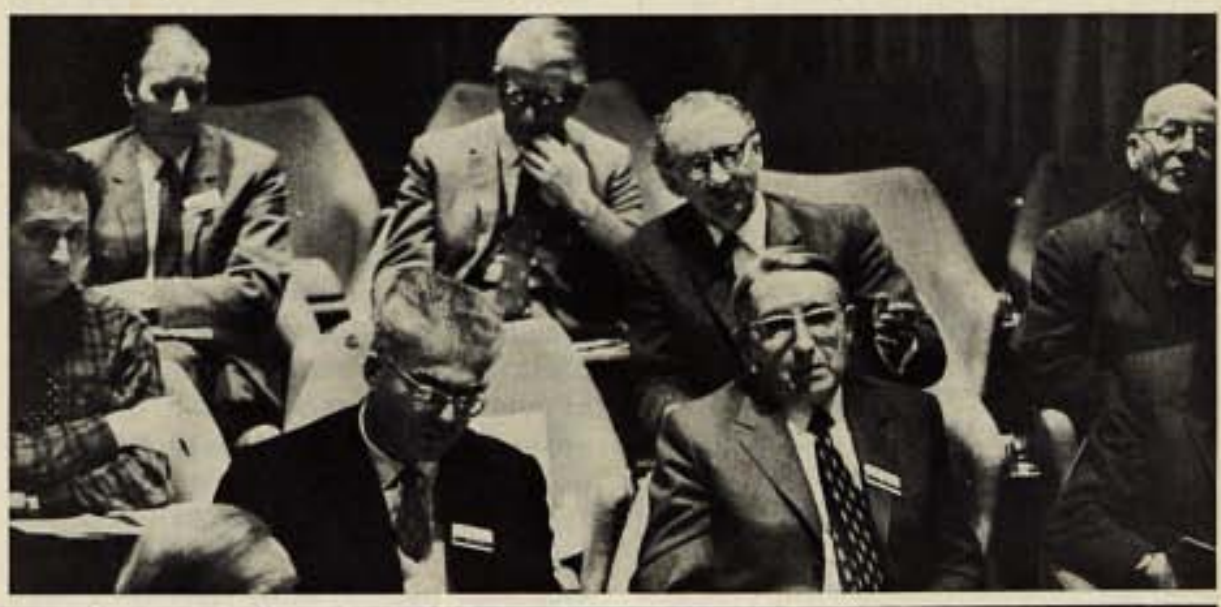

